\title{
Markets for Attention: Will Postage for Email Help?
}

\author{
Robert E. \\ Kraut $^{1}$ \\ Shyam \\ Sunder $^{2}$ \\ James \\ ${ }^{1}$ Carnegie Mellon University \\ 5000 Forbes Avenue \\ Pittsburgh, PA 15213 \\ \{Robert.Kraut|jmh|Rahul.Telang| \\ Darrin.Filer|Matt.Cronin\}@cmu.edu \\ +1412 268-7694
}

\author{
Rahul \\ Telang ${ }^{1}$ \\ Darrin \\ Filer $^{1}$ \\ Cronin ${ }^{1}$ \\ ${ }^{2}$ Yale University \\ PO Box 208200 \\ 135 Prospect Street \\ New Haven CT 06520-8200 \\ Shyam.Sunder@,Yale.edu \\ $+12034326160$
}

\begin{abstract}
Balancing the needs of information distributors and their audiences has grown harder in the age of the Internet. While the demand for attention continues to increase rapidly with the volume of information and communication, the supply of human attention is relatively fixed. Markets are a social institution for efficiently balancing supply and demand of scarce resources. Charging a price for sending messages may help discipline senders from demanding more attention than they are willing to pay for. Price may also help recipients estimate the value of a message before reading it. We report the results of two laboratory experiments to explore the consequences of a pricing system for electronic mail. Charging postage for email causes senders to be more selective and send fewer messages. However, recipients did not use the postage paid by senders as a signal of importance. These studies suggest markets for attention have potential, but their design needs more work.
\end{abstract}

\section{Keywords}

Computer mediated communication, electronic mail, empirical studies, economics, markets, social impact, spam.

Permission to make digital or hard copies of all or part of this work for personal or classroom use is granted without fee provided that copies are not made or distributed for profit or commercial advantage and that copies bear this notice and the full citation on the first page. To copy otherwise, or republish, to post on servers or to redistribute to lists, requires prior specific permission and/or a fee.

CSCW'02, November 16-20, 2002, New Orleans, Louisiana, USA.

Copyright 2002 ACM 1-58113-560-2/02/0011...\$5.00.

\section{INTRODUCTION}

As Herbert Simon noted over two decades ago, with the increasing capability of computers to generate, store, and transmit information, "A wealth of information" can lead to a "poverty of attention" (Simon, 1997). At about the same time, Poole et al. (1984) empirically demonstrated that the supply of information has been growing faster than our ability to consume it. Over the past hundred years, the volume of words and images available in many forms has grown exponentially, much faster than the number of recipients and the time they can devote to processing the information. A higher proportion of the information sent remains unread by many who could benefit from it, and is "wasted." This glut of information makes it increasingly difficult for the recipients to find what is relevant, useful or enjoyable.

This imbalance between the wealth of information and the poverty of attention is manifest in scientific literature, entertainment, conventional and electronic media, web sites, and correspondence. In this article, we consider the case of electronic mail.

\section{Modeling Electronic Communication}

Electronic technology has cut the cost of delivering messages by orders of magnitude. Relative to the fixed cost of hardware and software, the marginal cost of delivering a message is negligible. Unlike traditional means of delivering messages, cost recovery is not important to ensure continuation of service. Indeed, for early decades of the Internet, the U.S. government paid most of this cost through research grants, creating the practice and expectation of free electronic messaging. 


** Biggest Marketing Secret Revealed **
$* * 2$ Million E-Mail Addresses $\$ 49.95 * *$
I have been marketing on the Internet for one
year now. I trade e-mail databases with many
people, plus I have several other sources which I
obtain them from. Have you been looking for
the best way to promote your business, product
or service, and get results FAST? I have the
answer- BULK E-Mailing! There are other SO-
CALLED companies that will claim to give you
2 or 5 MILLION ADDRESSES- and they lie!
They will only give you 2 to 4 HUNDRED
THOUSAND!! ... Don't be RIPPED OFF by
these people. I have compiled a list of 2
MILLION ADDRESSES, and believe me,
there's 2 MILLION addresses, I GUARANTEE
it.

Figure 1. An excerpt from an email message by Eddie Davidson, eddie764@aol.com; original taken from http://www.nags.org/index.html.

A fundamental property of communication is that its value may be different for initiators and recipients. The marginal cost being negligible, the cost of sending a message to one or a thousand recipients is about the same. As a consequence, many companies send unsolicited electronic mail to advertise their goods and services, including pornography, get-rich-quick schemes, travel offers and computer products. Profit from even a small chance of finding a paying customer exceeds the small cost. Figure 1, a spam (unsolicited commercial email message sent to thousands) illustrates the scope of the problem. Most recipients do not value these messages.

These discrepancies between senders' and recipients' values apply to personal communication as well. Empirical studies show that the value of communication to the initiator exceeds the value to the recipient (Kraut \& Attewell, 1997; Perlow, 1999).

The result is that people send more messages than recipients would like to get. This tendency extends beyond commercial spamming to blind copies of personal or office mail, as well as jokes, stories and chain mail among acquaintances.

There are three basic mechanisms for dealing with these dysfunctional consequences of the discrepancy between value to senders and recipients of communication: filtering by recipients, regulation to deter senders, and charging senders a price.

\section{Filters}

Email filters and rules allow recipients to flag messages with a priority (Cranor, and LaMacchia, 1998). Filters do not efficiently balance the interests of senders and recipients for several reasons. First, they do not deter sending behavior unwanted by recipients. Commercial mailers can and do continually change or disguise the source of their messages in order to get through the filters. Second, designing and deploying effective filters consume scarce recipient resources, getting past them consumes sender resources, and messages never read consume network resources. Third, effective filter rules are difficult to program and maintain. Even with state-of-the-art artificial intelligence, it is beyond the capabilities of filter rules based solely on parsable attributes of messages to accurately distinguish between messages that recipient would or would not want to read (MacKay et al., 1989; Dumais, 1988). Fourth, filters are programmed by recipients without regard to the legitimate interests of the senders.

\section{Regulation}

For commercial telephone and fax solicitations - costs to recipients and senders being especially unbalanced in synchronous communication-federal and state governments have enacted laws to restrict the rights of senders. For example, recently the Federal Trade Commission (2002) proposed a national "do not call registry" to restrict unsolicited telemarketing. In 1996, the Canadian Radio-Television and Telecommunications Commission (CRTC) approved limits on the hours during which uninvited facsimile advertising can be sent to customers. Even for asynchronous postal mail, the US Postal Service prohibits "pandering advertisement which offers for sale matter which the addressee in his sole discretion believes to be erotically arousing or sexually provocative" (United States Government Printing Office, 1998). Sometimes industry groups regulate themselves to forestall stricter regulations by government. Because regulation threatens free expression, it has been restricted to commercial communication. Regulation is a blunt instrument; it doesn't respect the idiosyncratic value that particular senders and recipients place on their messages or track the time-varying value of attention, and obviously don't solve the general problem of mismatches.

\section{Pricing}

Pricing electronic mail to better balance the needs of senders and recipients is not a new idea. Academics have explored how it might work (Malone, Grant, Turbak, Brobst \& Cohen, 1987; Dwork, and Naor, 1993; Zandt, 2001). In 2002, the Daum Corporation, 
the largest Internet portal in Korea, began to charge bulk emailers a fee to send messages to its customers (http://info.daum.net). This is analogous to the practice of the US Postal Service charging different rates for express, registered, first class, second class, and bulk mail services. The pricing policy is based in part on the senders' assessment of the importance of a message reaching a designated recipient within a specified time period.

Zandt (2001) developed an economic model to explain why differential pricing of electronic mail should be helpful to both senders and recipients. The key insight is that by charging a small price to send a message, the pricing system shifts the task of screening messages from recipients, who don't know the content of a message, to senders, who do. Pricing rewards senders for being selective in sending messages. Senders' information about the recipients' interests enables the senders to be more selective, increasing the chances of their messages being relevant to and read by the recipients. We extend Zandt's model, to show that pricing improves communication efficiency most when the cost varies with the number of recipients and when the senders have information to differentiate among recipients in terms of their potential responsiveness to the message.

Zandt's and our formal models focus on benefits of sender selectivity. Prices can also signal the sender's assessment of the message to the recipient and help the latter decide which of the competing messages deserve attention. People open their express mail before their bulk mail. Credibility of the signal increases with the cost to the sender. A "high-priority" label on a message works only if the recipient has reason to believe, from prior experience or its cost to the sender, that such labels are not used indiscriminately.

Pricing of email is an example of using a market mechanism to allocate scarce resources-human attention in this case. Markets are social institutions that have evolved to solve difficult society-level optimization problems using information in possession of individuals (Hayek, 1945). We conjecture that a market for attention that charges senders for each message can, like many other markets, efficiently allocate the resources through decentralized decisions. It allows people to decide based on the value of the messages they wish to send and the value of their attention, without revealing private information. The model developed in the following sections predicts that charging a per-message price increases communicative efficacy, benefiting both heterogeneous recipients as well as senders who can discern this heterogeneity to some degree. We compare the data from two laboratory experiments to the predictions of the model.

\section{EMPIRICALLY TESTING A MARKET FOR ATTENTION}

Tools of economics can be used to reason about the consequences of different pricing schemes for communication. We first present a simple model to capture the intuition behind our hypothesis about pricing schemes (see Telang 2002 for details).

Let us assume that there are $m$ senders and $m$ recipients ${ }^{1}$. While there are many senders sending messages to a recipient, the recipient is interested in only one of the messages. The recipient suffers from information overload in that she can comprehend and respond to only $f$ of all messages received, ignoring the rest. Out of $m$ messages received, the probability of a given message being seen is $\min (1, f / m)$. If the recipient finds a message useful, she responds to the sender, who realizes a payoff $p$. The expected payoff to a sender from sending one message to each recipient is:

benefit $_{\text {sender }}=p_{\text {sender }} \times \min \left(1, \frac{\mathrm{f}}{\mathrm{m}}\right)$

Similarly, if we assume that recipient's payoff is $\delta$ when she receives, opens and responds to a sender's message, the expected gross benefit to the recipient from processing $f$ messages is:

benefit $_{\text {recipient }}=\delta_{\text {recipient }} \times \min \left(1, \frac{\mathrm{f}}{\mathrm{m}}\right)$

How will different pricing policies change the payoffs for senders and recipients?

\section{No Targeting Possible}

Flat Rate Pricing ${ }^{2}$

First consider the case where recipients are homogeneous or senders have no information to distinguish among them. Under flat rate pricing, senders pay a fixed amount $(C)$ to send an unlimited number of messages. If a sender finds it profitable to send a message to one recipient, he should send it to all recipients as marginal cost of sending each additional message is zero. If $C$ is low enough such that each sender's profit (which is equation (1) minus $C)$ is positive, then all senders will send messages to

${ }^{1}$ For ease of exposition, we make senders male and recipients female.

${ }^{2}$ Non-linear pricing strategies in different contexts have been studied extensively in economic literature (Wilson 1993) 
all recipients for a total of $m \times m$ messages. As the cost of communication $C$ rises, the sender's profit decreases until it becomes zero and all the senders cannot be sustained in business. However, each sender who remains in business would want to send a message to every recipient. The number and messageprocessing strategies of the recipients define the total size of the pie to be divided among the senders.

More interestingly, the benefit for recipients does not change with $C$. As the number of incoming messages falls, the effects of the rise in the probability $(\mathrm{f} / \mathrm{m})$ that she will open and read a message increases and the drop in the probability of receiving a message from a 'desirable sender' cancel each other out.

\section{Usage-Based Pricing}

Now consider the case when senders have to pay for each message sent to each recipient. We assume that there is a communication cost of $c>0$ per message and senders pay $c \times k$ to send a message to $k$ different recipients. The benefit functions (1) and (2) still apply; for calculating profits we subtract cost $c \times k$.

Though the marginal cost $c$ of sending a message is non-zero, the senders either send a message to all recipients or to none. Since senders have no information about individual recipients, they send messages if and only if the expected benefit of sending a message exceeds $c$. The results derived from flat rate pricing also hold when applied to usage-based pricing. It should be noted that depending on $c$ and $C$, the number of senders sending messages and hence total volume of communication will be different from flat rate case but the overall benefits to senders and receivers will be unchanged. Qualitatively, the nature of the equilibrium remains same.

To summarize, total benefits in flat rate and usagebased pricing for senders and recipients are the same. Moreover, when senders have no differentiating information about the recipients, the total benefits for senders and recipients are not affected by the change in prices under either pricing scheme. However, under both pricing schemes the total communication declines with increase in price.

\section{Targeting Recipients}

Consider the case where recipients are heterogeneous and the senders can distinguish among them in terms of their likely value. Hence, senders can partially rankorder recipients. With usage-based pricing, the sender will target messages, sending them only to those recipients for whom the benefit of sending the message is more than its cost. However, with flat rate pricing, as long as there is even a small probability of a

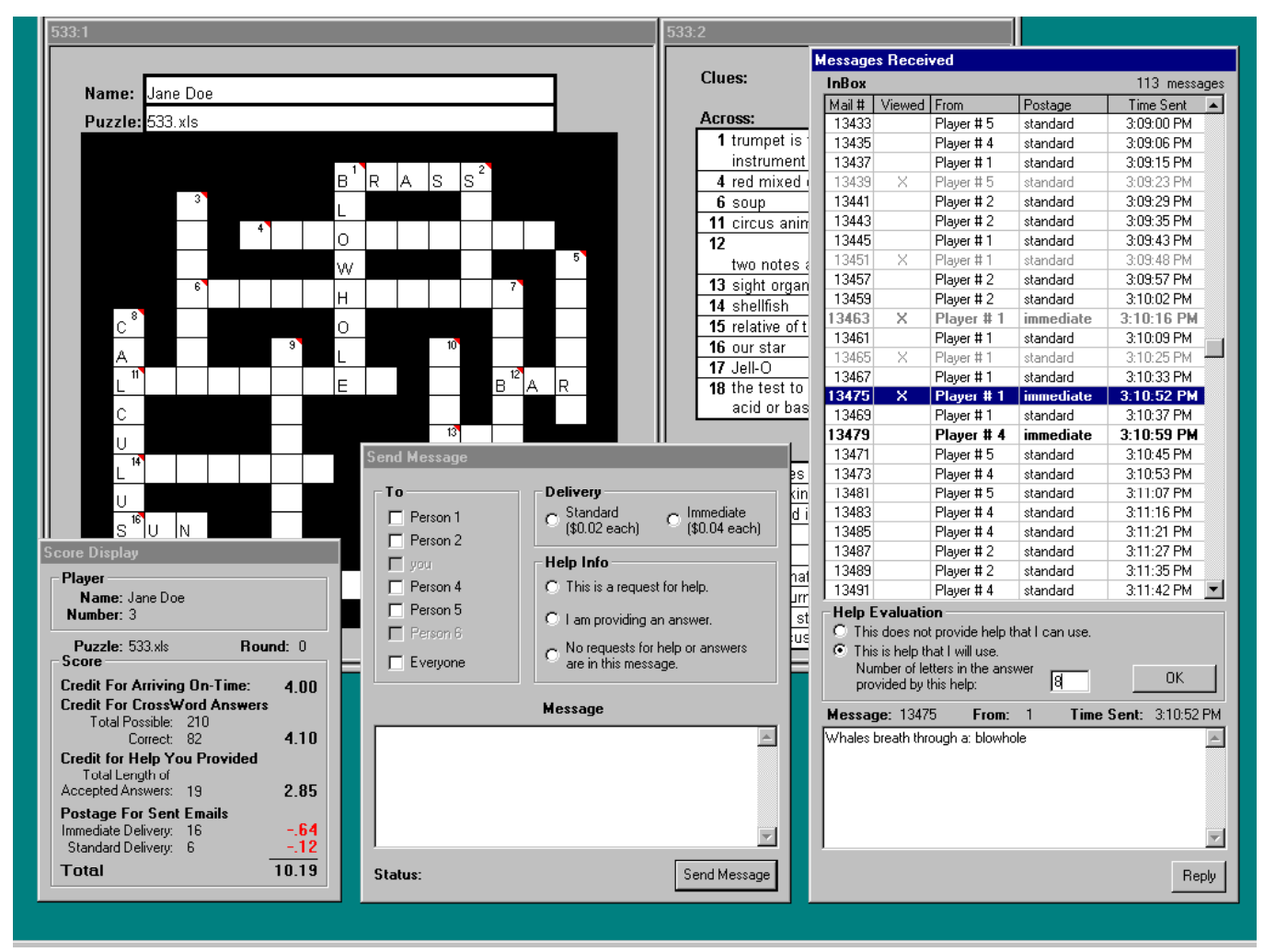

Figure 2: Crossword puzzle controls 
recipient being the 'right' recipient, there will be no targeting and the message will be sent to all recipients. Holding cost of communication constant, the number of messages in usage-based pricing will be less than in flat rate pricing. Moreover, targeting increases benefits for both senders and recipients. In summary, the sender's ability to target recipients, along with the usage-based pricing scheme, leads to higher benefits to senders and recipients

It should be noted, however, that while usage-based pricing reduces the amount of communication and information overload, charging too high a price could lead to sub-optimal benefits for both senders and recipients. The cost should be such that the number of messages sent is equal to $f$, which is the maximum number of messages processed by the recipients. If the communication cost is more, then the number of messages will be too low, reducing the benefit for both sender and recipient. Too high a cost can reduce the number of messages below $f$, hence reducing the benefit for both sender and recipient. On the other hand, if the cost is too low, it may not reduce the number of messages enough to prevent information overload.

\section{TESTING A MARKET FOR ATTENTION}

\section{Overview.}

We conducted and report on two laboratory experiments to test whether charging "postage" for email can improve social welfare by effectively matching the communication needs of senders and recipients, thereby efficiently allocating a community's attention. As in most experiments, our results only show what the effects of an intervention-in this case, per message pricing-can be under controlled circumstances. Producing the same effects in the real world is a further research and design challenge.

In these experiments, players earned money by completing a crossword puzzle (the foreground task). They could ask other players for help, to improve their crossword scores, and earn additional money by sending answers to them. They could label their communication as high-priority or standard-priority. They performed these activities under two different postage regimes. Under one, they were charged a flat rate for every message they sent, regardless of the number of recipients or priority condition. Under the second, they paid per recipient and paid more for sending high-priority than for standard-priority mail. We provide the details below.

The experiments simulated a situation with the following conditions: (A) Players had a foreground task-completing crossword puzzles-whose performance was personally valuable, but whose value varied with personal endowment and goals. This foreground task determined the opportunity costs of the time players spent processing email. (B) Players had an incentive to send electronic mail to other players, which may or may not have been of value to the recipients. (C) Players received more messages than they could read in the time provided. Under these conditions, players had to allocate their time between the foreground and communication tasks and among the messages they received. (D) Players were differentiated in terms of the types of messages they could answer.

We expected that:

H1a: Usage-based pricing would cause senders to ration communication. They would send fewer messages, send each message to fewer recipients, and use high-priority designation less often.

H1b: Usage-based pricing would cause senders to better target their messages, sending fewer to irrelevant addressees.

$\mathrm{H} 2 \mathrm{a}$ : Usage-based pricing would cause recipients to read and respond to a higher proportion of the messages they received.

$\mathrm{H} 2 \mathrm{~b}$ : Usage-based pricing would increase the credibility of a high-priority signal and cause recipients to differentiate more between standard and high-priority messages.

H3: A postage regime that regulates message volume (H1) and allocation of attention (H2) leads to more effective allocation of attention. Therefore, under usage-based pricing players should earn more money.

\section{Experiment 1}

\section{Experimental procedure:}

Subjects and task. Four to six university undergraduates played a game that required each to fill out a unique crossword puzzle in each of five rounds of ten minutes each.

The participants received a monetary reward for their performance in the crossword puzzle game, based on two criteria. First, they earned $\$ .05$ for each correct letter they answered on the crossword puzzles. Second, they earned money for helping others. They were given clue sheets containing clues and answers for words appearing on other players' puzzles.

Subjects could send email messages to one or more players to request help or to provide help. To simplify data analysis, players were required to characterize the content of their messages and were allowed to include 
only a single query or answer per message. Upon receiving a message purporting to contain help, the recipient indicated whether he or she would use the answer. If so, the sender was awarded $\$ 0.15$ per letter in the answer.

Although exchanging messages was potentially rewarding, it also competed for the time a subject could work on the puzzle, which was an alternative way to earn money. To emphasize the opportunity cost of communicating, we imposed a time delay when players read their mail. After clicking on a message, player had to wait five seconds before the text of the message was displayed. During this time they could not work on their puzzles.

Subjects could send messages using either standard or high-priority. Standard-priority messages were delivered in approximately 20 seconds and appeared in a player's inbox in standard text. High-priority messages were delivered immediately and appeared in the recipient's inbox in bold text.

To increase the burden of processing messages, a server sent out email approximately every seven seconds. The server-generated messages appeared to come from another player. The server-generated messages were all sent via standard-priority.

None of the messages contained a subject field. As a result, they revealed few cues to their value before being opened. To determine whether a message was potentially valuable, recipients had to open it or to rely upon its priority level. Elimination of the subject field enabled us to focus the experiment on the consequences of pricing on communication, which required costly attention of recipients. Given the simple communication required for the task, we could not allow the subject line to become a substitute for the main message itself.

Postage regimes. We randomly assigned all subjects in a session to one of two different postage regimes - an inexpensive, fixed-rate regime and a more costly, variable-rate regime.

In the fixed-rate postage condition, both standard and high-priority messages cost $\$ .02$ each, independent of the number of addressees. In the variable-rate postage condition, standard messages cost $\$ .02$ and highpriority messages cost $\$ .04$. Additionally, postage was charged per addressee. Thus, in a fixed-rate session a high-priority message sent to three people would cost \$0.02 (\$.02 x 1 message), but it would cost \$0.12 (\$.04 $\mathrm{x} 3$ addressees) in the variable-rate session.

\begin{tabular}{|c|c|c|c|}
\hline \multirow[t]{2}{*}{ Dependent variable } & \multicolumn{2}{|c|}{ Postage Regime } & $p$ \\
\hline & Fixed & Variable & \\
\hline \multicolumn{4}{|l|}{ Sending behavior } \\
\hline $\begin{array}{l}\text { Unique messages } \\
\text { sent }{ }^{b}\end{array}$ & 19.2 & 12.5 & .13 \\
\hline $\begin{array}{l}\text { Recipients per } \\
\text { message }^{\text {a }}\end{array}$ & 3.0 & 2.4 & .01 \\
\hline $\begin{array}{l}\% \text { high priority } \\
\text { message }^{\text {a }}\end{array}$ & $90 \%$ & $68 \%$ & .01 \\
\hline \multicolumn{4}{|l|}{ Attention behavior } \\
\hline$\%$ messages read $^{a}$ & $57 \%$ & $77 \%$ & .01 \\
\hline $\begin{array}{l}\% \text { messages replied } \\
\text { to a }\end{array}$ & $12 \%$ & $17 \%$ & .06 \\
\hline$\%$ help accepted ${ }^{\mathrm{a}}$ & $10 \%$ & $17 \%$ & .60 \\
\hline \multicolumn{4}{|l|}{ Performance } \\
\hline Total earnings ${ }^{b}$ & $\$ 2.64$ & $\$ 1.71$ & .05 \\
\hline $\begin{array}{l}\text { Puzzle completion } \\
\text { earnings } b\end{array}$ & $\$ 2.26$ & $\$ 2.08$ & .45 \\
\hline Reward for help ${ }^{b}$ & $\$ .79$ & $\$ 85$ & .47 \\
\hline Paid for postage ${ }^{b}$ & $\$ .40$ & $\$ 1.21$ & .10 \\
\hline
\end{tabular}

Table 1: Experiment 1. Effects of postage regime $(\mathrm{N}=1474$ messages nested within 5 rounds per player nested within 55 players nested within 11 experimental sessions)

a Based on a hierarchical linear model, with the message as the unit of analysis.

b Based on a hierarchical linear model, with the player nested within round as the unit of analysis

earnings during a round-the sum of the amounts earned from completing puzzles and offering help less the cost of postage.

Because messages were nested within players within rounds of the experiment and because players were nested within experimental session, we used hierarchical linear models to account for the nonindependence of observations (Bryk \& Raudenbush, 1992). For analyses about particular messages and responses to them, the message was the unit of analysis. For analyses about communication value and performance outcome, the player within round within session was the unit of analysis. In all models, the university where the session was run, the number of players involved, and the round within session were included as control variables.

\section{Results}

Subjects used high-priority frequently, in $77 \%$ of messages. Across all conditions, they spent $\$ 0.91$ per 
round on postage. Forty-five percent of their messages were questions and 52 percent were answers. Sixtyfour percent of their messages were read. Fifteen percent received responses.

\section{Effects of postage regime on message-sending.}

The postage regime influenced message-sending in economically sensible ways. Table 1 shows these effects. In the variable-rate postage condition (paying per recipient and for high-priority messages), players rationed their messages. They sent a third fewer messages per round $(\mathrm{p}<.13)$, addressed each to fewer recipients $(\mathrm{p}<.01)$ and used the high-priority delivery option less $(\mathrm{p}<.01)$.

\section{Effects of message-sending behavior on attention}

The way players sent messages had powerful consequences for the attention that addressees paid to them. In the variable-rate condition, players read a higher percentage of the messages $(p<.01)$ and replied to more of them $(\mathrm{p}<.06)$. They could pay more attention to the fewer messages received under the variable-rate postage. Players read a higher proportion of messages when fewer originals were sent $(r=-.14$, $\mathrm{p}<.02$ ) and when each original was sent to fewer recipients $(\mathrm{r}=-.31, \mathrm{p}<.001)$.

Players read high-priority messages more often $(\mathrm{r}=.72$, $\mathrm{p}<.0001$ ), partly because they could be sure that highpriority messages were not spam. Seventy-five percent of the high-priority messages were read versus only 12 of the standard-priority messages.

We had expected high-priority messages to have a greater impact when this designation was costly (i.e., in the variable-rate postage condition). Message

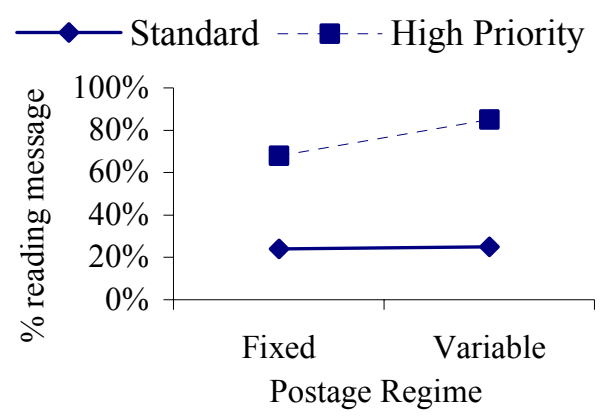

Figure 3: Interaction of postage regime and priority of a message on the likelihood of reading it

reading frequencies in Figure 3 are consistent with this prediction, although the postage regime $\mathrm{X}$ priority interaction did not achieve statistical significance $(\mathrm{F}(1,1315)=2.22, \mathrm{p}<.13)$.

\section{Effects of postage regime on economic outcomes}

We had expected that these effects of the variable-rate postage regime-reducing the volume of communication and increasing readership-would help players more efficiently allocate their time between their foreground task (the crossword puzzles) and messaging. We expected them to earn more money under the variable postage condition, at least before subtracting postage costs.

This prediction was disconfirmed. Subjects in the variable-rate postage condition netted significantly less than those in the fixed-rate postage. They earned insignificantly less for completing puzzles, but spent substantially more for sending messages (see Table 1).

\section{EXPERIMENT 2}

Experiment two was designed to simulate a condition where senders and recipients of messages had mixed motives. In Experiment 1, each message had the potential to benefit both the sender and the recipient. People who asked questions benefited if they received good answers, and players who sent answers received rewards if their answers were used. We introduced mixed motives by letting some players send a new type of message - advertisements. Senders were rewarded when recipients read advertisements, but recipients were penalized because opening advertisement messages left them less time to do their crossword puzzles.

In addition, Experiment 2 was designed to explicitly test the prediction that people would more precisely target their messages when communication was more costly. We did this by assigning players domains of expertise and testing to see whether players were more likely to address their questions to the experts under costly communication.

Finally, Experiment 2 was designed to test the hypothesis that pricing communication would change senders' behavior most when they when recipients were heterogeneous. We did this by creating two classes of messages. Recipients were heterogeneous with regard to questions, because sender benefited more when they were sent to a domain expert. However, recipients were homogeneous with regard to advertisements; senders benefited equally regardless of which recipients read their advertisements. 


\section{Experimental procedure}

Procedures for Experiment 2 were very similar to Experiment 1, with the following differences.

Advertising: All subjects could send questions and answers, as in Experiment 1. In addition, two subjects in each experimental session could send advertising messages, earning \$.25 per recipient who opened an advertisement. Opening an advertisement consumed 5 seconds of the recipient's time.

Expertise. As in Experiment 1, answers to puzzles were distributed among players. Answers were distributed so that each player was an "expert" in one domain. The expert was 80 percent likely to have an answer versus 20 percent for a random player. All players were given a table showing the distribution of

\begin{tabular}{|c|c|c|c|}
\hline \multirow[t]{2}{*}{ Dependent variable } & \multicolumn{2}{|c|}{ Postage Regime } & \multirow[t]{2}{*}{$p$} \\
\hline & Fixed & Variable & \\
\hline \multicolumn{4}{|l|}{ Sending behavior } \\
\hline $\begin{array}{l}\text { Unique messages } \\
\text { sent }{ }^{b}\end{array}$ & 13.6 & 9.8 & .01 \\
\hline $\begin{array}{l}\text { Recipients per } \\
\text { message }^{\text {a }}\end{array}$ & 3.6 & 3.0 & .02 \\
\hline $\begin{array}{l}\% \text { high priority } \\
\text { message }^{a}\end{array}$ & $81 \%$ & $41 \%$ & .001 \\
\hline $\begin{array}{l}\% \text { queries matching } \\
\text { addressee's expertise } \\
\text { a }\end{array}$ & $32 \%$ & $45 \%$ & .01 \\
\hline \multicolumn{4}{|l|}{ Attention behavior } \\
\hline$\%$ messages read ${ }^{a}$ & $42 \%$ & $45 \%$ & .99 \\
\hline $\begin{array}{l}\% \text { messages replied } \\
\text { to }{ }^{a}\end{array}$ & $04 \%$ & $05 \%$ & 60 \\
\hline \multicolumn{4}{|l|}{ Performance } \\
\hline Total Earnings ${ }^{b}$ & $\$ 2.07$ & 1.47 & .01 \\
\hline $\begin{array}{l}\text { Puzzle Completion } \\
\text { Earnings }{ }^{b}\end{array}$ & 1.61 & 1.39 & .02 \\
\hline Reward for help ${ }^{b}$ & .76 & .66 & .47 \\
\hline $\begin{array}{l}\text { Reward for } \\
\text { advertising }\end{array}$ & .06 & .23 & .19 \\
\hline Paid for postage ${ }^{b}$ & .36 & .81 & .001 \\
\hline
\end{tabular}

Table 2: Experiment 2. Effects of postage regime $(\mathrm{N}=7609$ messages nested within 5 rounds per player nested within 120 players nested within 24 experimental sessions)

a Message nested within player as the unit of analysis.

\footnotetext{
b Dlovar nactad writhin round oc tha unit of anolvacic
}

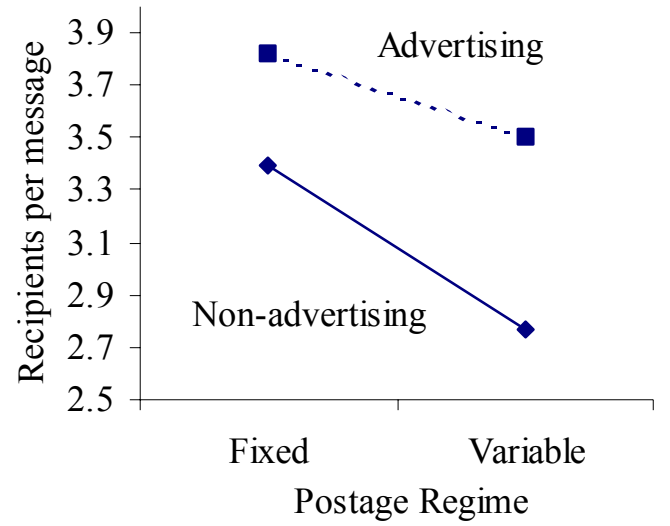

Figure 4: Interaction of message type and postage rate on number of recipients per messasge.

expertise.

Results

Subjects used high-priority for 56 percent of the messages. Across all conditions, they spent \$.64 per round on postage. Thirty-three percent of the messages were questions, 45 percent were answers, and 23 percent were advertisements. They read 55 percent of the messages and replied to 45 percent of the queries.

\section{Effects of postage regime on message sending}

Costly communication influenced participants' sending behavior in economically sensible ways. Under the variable-rate postage, participants sent fewer messages, addressed each message to fewer participants, and used high-priority less often. In addition, as predicted, subjects in the variable-rate postage condition were more likely to target their queries to the experts (see Table 2).

Players sent most of their messages to multiple recipients, and did so more for advertisements (93\%) than for questions $(74 \%)$ or answers $(75 \%)$. Consistent with our model, variable-rate postage inhibited sending to multiple recipients most when senders could differentiate among recipients. The significant interaction between message type and postage regime shows that costly communication inhibited multiple addressees more for questions and answers than for advertising (Figure 4).

\section{Effects of postage regime on attention}

While recipients read and replied to slightly more of their messages in the variable-rate postage condition, neither effect approached statistical significance. Players were more likely to read high-priority messages (59\% read high-priority message read versus $41 \%$ of standard-priority messages). Contrary to 
expectations, costly postage did not enhance the signaling power of the high-priority option $(\mathrm{p}>.50)$.

Participants were 18\% less likely to read advertising messages than those containing questions or answers $(\mathrm{p}<.001)$. Players could not know the type of message before incurring the cost of opening it; senders' identity was their only cue to content. Recipients gradually learned to open fewer messages from advertising-enabled players than from others.

\section{Effects of postage regime on economic outcomes}

In terms of outcomes, subjects in variable-rate postage sessions earned reliably less than subjects in fixed-rate sessions. They earned less from completing the puzzles and paid more for postage (see Table 2).

\section{DISCUSSION}

These experiments examined the consequences of making electronic communication more costly, by charging per address and imposing a surcharge for high-priority messages. In both experiments, increasing usage-based postage had consequences that follow from our economic model. Under conditions of costly, variable-rate communication, senders sent fewer messages, sent each message to fewer recipients, and used the high-priority option less. Experiment 2 demonstrated that when communication was more costly, senders were more likely to target their messages to relevant people. Costly communication inhibited spamming most when senders could differentiate among recipients.

Evidence was strong that message-sending behavior influenced the frequency of recipients' reading and responding to messages. Players read a higher proportion of messages when they had fewer to read and when they were directed to fewer addressees. In Experiment 1 (but not in Experiment 2) players read and responded to a higher proportion of messages under costly communication. However, in neither experiment did the cost of high-priority messages change their signaling power.

These changes in the economics of communication made it more efficient, reducing volume and increasing relevance. While one would intuitively believe that reduction in the volume of communication would lead to better payoffs, our model clearly points out that this is not so. As we demonstrated, both flat rate and usage-based rates reduce the volume but do not necessarily increase the benefits. Benefits increase only when targeting is possible. Our experiments did in fact allow for targeting, and senders targeted more under usage-based pricing. However, we suspect that the overall social welfare did not increase under usage- based pricing because we chose parameters that did not make message recipients sufficiently heterogeneous.

Players benefited from asking others for help and were rewarded for providing help. When players communicated less, they received fewer of these benefits. However, pricing has to be done so that it induces the users to send messages to relevant recipients only. But as we mentioned before, too high a price may lead to sub-optimal benefits by reducing the communication. It is possible that with the parameters we chose in our experiments, the costs of dealing with unwanted communication were not as large as the opportunity costs of foregoing relevant communication.

Our model points out that both the sender's ability to target recipients and the right pricing scheme are required for higher communication efficiency and higher benefits to senders and recipients. Similarly, Zandt (2001) hypothesized that the benefits from postage would depend upon the diagnosticity of the cues senders use to address their messages. Both sender and recipient benefit from relevant communication. Empirical studies that vary the diagnosticity of the information as well as targeting and pricing are needed to test this prediction further.

If further theoretical modeling and empirical research demonstrate the potential of markets for attention, we must overcome a number of challenges before these ideas can be implemented in real-world systems. Designing the appropriate pricing mechanism for messages, and convincing people to accept having to pay for heretofore free services, are the challenges.

The scheme illustrated here is only one of the many possible pricing mechanisms. While this type of pricing could reduce the volume of messages and improve targeting, it cannot, by itself, induce recipients to read messages they think are not in their interest. It may well be that an email regime which incorporates postage in the form of transfer payments among senders and recipients (assuming that the costs of operating the system are small enough) may be better for the community. ${ }^{3}$ The sender can buy the recipient's time, as in some discounted telephone services that deliver advertising. Broadcast TV and

3 Messaging undoubtedly has socio-psychological consequences beyond what can be captured in economic models. Such factors are more important among acquaintances than strangers. For this reason, we confined our investigation to communication among strangers. 
radio also provide news and entertainment in exchange for willingness to receive advertising messages.

It will be difficult to change public attitudes towards charging for what has been a free service since its early days. However, this transition has been done with other communication services, including the shift from flat-rate pricing of telephone service to metered pricing and the shift from free broadcast TV to feebased cable and pay-per-view TV. Given sufficient societal benefits, the shift is possible.

\section{ACKNOWLEDGMENTS}

This project was supported by the Intel Corporation. Catherine Chan, Jessica Morgan, Yuquin Ren and Allan Roth helped to run the experiments. Nicole Lazard provided statistical advice.

\section{REFERENCES}

1. Bryk, A. \& Raudenbush, S. (1992). Hierarchical linear models: Applications and data analysis methods. Newbury Park, CA: Sage.

2. Boyle, C. D. B., \& Clarke, M. R. B. (1985). An Intelligent Mail Filter. Proceedings of the HCI'85 Conference on People and Computers: Designing the Interface (331-341).

3. Cranor, L. F. and LaMacchia, B. A. (1998). Spam! Communications of the ACM. 41(8), 74-83.

4. Dwork, C. and Naor, M. (1993). Pricing via processing for combating junk mail. In E. Brickell, (Ed). Advances in Cryptology-Crypto '92: Lecture Notes in Computer Science 740, (pp139-147), NY: Springer-Verlag.

5. Federal Trade Commission. (2002). Telemarketing Sales Rule, 16 CFR Part 310. Washington, DC: U.S. Printing Office.

6. Hayek, Friedrich A.. (1945). The Uses of Knowledge in Society. American Economic Review, 35(4), 519-30.

7. Horvitz, E., Jacobs, A., \& Hovel, D. (1999). Attention-Sensitive Alerting. Proceedings of UAI '99, Conference on Uncertainty and Artificial Intelligence, (pp 305-313). Stockholm, Sweden.

8. Kraut, R. E. \& Attewell, P. (1997). Media use in a global corporation: Electronic mail and organizational knowledge. In S. Kiesler (Ed.) Culture of the Internet. (pp. 323-342). Mahwah, NJ: Erlbaum.
9. Mackay, Wendy E. (1988). Diversity in the Use of Electronic Mail: A Preliminary Inquiry. $A C M$ Transactions on Office Information Systems,.6(4), 380-397

10.Malone, T.W, Grant, K.R., Lai, K., Rao, R. \& Rosenblitt, D. (1987) Semi-structured messages are surprisingly useful for computer-supported coordination. ACM Transactions on Office Information Systems, 5(2), 115-131.

11. Malone, T.W., Grant, K.R., Turbak, F.A., Brobst, S.A. and Cohen, M.D., (1987). Intelligent information-sharing systems. Communications of the ACM, 30(5), 390-402.

12. Mayer, M. (1977). The telephone and the uses of time. In I. de Sola Pool (Ed.) The social impact of the telephone. (pp. 225-245). Cambridge, Massachusetts: MIT Press.

13. Perlow, L. A. (1999). The time famine: Toward a sociology of work time. Administrative Science Quarterly, 44(1), 57-81.

14.Pollock, Stephen (1988). A Rule-Based Message Filtering System. ACM Transactions on Office Information Systems, 6(3), 232-254.

15.Pool, I., Inose, H., Takasaki, N. \& Hurwitz, R. (1984). Communication flows: A census in the United States and Japan. New York: NorthHolland.

16. Simon, H. A. (1982). Designing organizations for an information-rich world: Models of Bounded Rationality (pp. 171-185). Cambridge, MA: MIT Press.

17. Telang, Rahul. (2002). Information Overload and Pricing of Communication Services. Carnegie Mellon University Working Paper.

18. United States Government Printing Office (1998). United States Code, Title 39 POSTAL SERVICE. Prohibition of pandering advertisements

19. Wilson, R.B. (1993). Nonlinear Pricing. New York: Oxford University Press.

20.Zandt, van T. (2001, May 18). Information overload in a network of targeted communication. Downloaded from http://zandtwerk.insead.fr, September 14, 2001. 